\title{
SUPORTE AVANÇADO DE VIDA NA PARADA CARDIORRESPIRATÓRIA: ASPECTOS TEÓRICOS E ASSISTENCIAIS
}

\author{
Amanda Fonseca Moura LAFETÁ ${ }^{1}$ \\ Bruno Pereira de PAULA ${ }^{1}$ \\ Cássio de Almeida LIMA ${ }^{1 *}$ \\ Luiz Eduardo Silveira LEITE ${ }^{2}$ \\ Patrícia Alves PAIVA ${ }^{1}$ \\ Harley Medawar LEÃO ${ }^{3}$ \\ Henrique Andrade BARBOSA ${ }^{3}$ \\ Mirela Lopes de FIGUEIREDO ${ }^{3}$ \\ Neiva Aparecida Marques DIAMANTINO ${ }^{3}$ \\ Edna de Freitas Gomes RUAS ${ }^{3}$
}

${ }^{1}$ Enfermeiro. Graduado pela Universidade Estadual de Montes Claros (UNIMONTES).

${ }^{2}$ Acadêmico do Curso de Graduação em Enfermagem da UNIMONTES.

${ }^{3}$ Enfermeiro. Professor do Departamento de Enfermagem da UNIMONTES.

*Autor correspondente: cassio-enfermagem2011@ hotmail.com

\section{Recebido em: 24/02/2015 - Aprovado em: 29/06/2015 - Disponibilizado em: 15/07/2015}

\begin{abstract}
RESUMO
Este estudo teve como objetivo discutir os aspectos teóricos e assistenciais envolvidos na assistência durante o suporte avançado de vida realizado durante a parada cardiorrespiratória. Trata-se de estudo descritivo, do tipo revisão narrativa da literatura, ancorada na Diretriz de Ressuscitação Cardiopulmonar e Cuidados Cardiovasculares de Emergência da Sociedade Brasileira de Cardiologia publicadas em 2013 e artigos científicos publicados nos últimos cinco anos. A revisão permitiu apresentar as recomendações mais atuais e indicadas por fortes evidências para a assistência durante o suporte avançado de vida na parada cardiorrespiratória. Os estudos indicaram os aspectos relativos à necessidade de constante capacitação, treinamento, educação permanente em serviço para os profissionais, e ainda para leigos no assunto, a fim de se ter uma assistência de qualidade. Ressalta-se que o conhecimento acerca da temática em questão é de suma relevância para que se prestem cuidados ancorados em boas práticas recomendadas por fortes evidências e que, dessa maneira, culminem numa assistência segura e de alta qualidade.
\end{abstract}

Palavras-chave: Ressuscitação Cardiopulmonar. Parada Cardiorrespiratória. Assistência ao Paciente. Enfermagem.

\section{ABSTRACT}

This study aims to discuss the theoretical aspects and clinicians involved in care during the basic and advanced life support performed during a cardiorespiratory arrest. This is a descriptive study, type narrative review of the literature, anchored in the development of the Guideline for Cardiopulmonary Resuscitation and Emergency Cardiovascular Care of the Brazilian Society of Cardiology published in 2013 and scientific articles published in the last five years. The review allowed us to present the more current recommendations and indicated by strong evidence for assistance during the advanced life support in the cardiorespiratory arrest. The studies indicated the aspects relating to the need for constant training, permanent in-service education for professionals, and even to lay people in the subject, in order to have a quality assistance. It should be noted that the knowledge about the topic in question is of the utmost importance to provide care anchored in good practices recommended by strong evidence and that, in this way, culminating in a safe handling and of high quality.

Descriptors: Cardiopulmonary Resuscitation. Cardiac Arrest. Patient Care. Nursing.

\section{INTRODUÇÃO}

A luta pela manutenção da vida, que ocorre nas diversas situações de urgência e emergência, representa o princípio básico e fundamental que norteia o desenvolvimento técnico-científico na área da saúde. Entre as emergências que ameaçam a vida, a parada cardiorrespiratória (PCR) configura-se como a mais temida, uma vez que a chance de sobreviver está diretamente relacionada ao 
atendimento rápido, seguro e eficaz (ALVES; BARBOSA; FARIA， 2013; GOLIN; SPROVIERI, 2008). Apesar de avanços nos últimos anos relacionados à prevenção e a tratamento, muitas são as vidas perdidas anualmente no Brasil, relacionadas à parada cardiorrespiratória (PCR), ainda que não se tenha a exata dimensão do problema pela falta de estatísticas robustas a esse respeito. Os avanços também se estendem à legislação sobre acesso público à desfibrilação e obrigatoriedade de disponibilização de desfibrilador externo automático (DEA), assim como no treinamento em ressuscitação cardiopulmonar (RCP). Pode-se estimar algo em torno de 200.000 PCRs ao ano no Brasil, sendo metade dos casos em ambiente hospitalar e a outra metade em ambiente extra-hospitalar (GONZALEZ et al., 2013; SOCIEDADE BRASILEIRA DE CARDIOLOGIA, 2013).

Estima-se que a maioria das PCRs em ambiente extra-hospitalar sejam em decorrências de ritmos como fibrilação ventricular e taquicardia ventricular sem pulso, enquanto que, em ambiente hospitalar, a atividade elétrica sem pulso e a assistolia respondam pela maioria dos casos. Esta diferença deve-se provavelmente a um perfil diverso do paciente internado, em que a PCR é um evento que reflete uma deterioração clínica progressiva, diferentemente do que acontece fora do hospital, em que a maioria das PCRs é súbita e devida, em grande parte, a arritmias decorrentes de quadros isquêmicos agudos ou a problemas elétricos primários (SOCIEDADE BRASILEIRA DE CARDIOLOGIA, 2013).

A PCR é uma emergência relativamente frequente em qualquer serviço de atendimento de emergência, e significa a cessação dos batimentos cardíacos e dos movimentos respiratórios. Com a evolução das técnicas de reanimação cardiopulmonar, desenvolvimento de drogas, aperfeiçoamento de equipamentos e treinamento de leigos e profissionais, milhares de vidas são salvas em todo o mundo (GOLIN; SPROVIERI, 2008; TREVILATO, 2001).

Segundo a Sociedade Brasileira de Cardiologia (2013), esforços no sentido de reunir o conhecimento científico a respeito da PCR e de estabelecer um padrão e uniformidade para o seu tratamento vêm sendo realizados desde o início dos anos 1960. Com o estabelecimento da Aliança Internacional dos Comitês de Ressuscitação (ILCOR), esses esforços foram sistematizados através de uma ampla revisão da literatura científica publicada atinente ao tema, culminando com o primeiro consenso científico internacional, no ano de 2000. Frente ao exposto, tornam-se imprescindíveis estudos que apresentem o conhecimento acerca das manobras de ressuscitação, uma vez que as diretrizes que norteiam o 
atendimento à PCR mudam a cada cinco anos, o que exige, dos profissionais, atualização constante na área. Ainda, estudos possibilitam aos serviços de saúde a elaboração de estratégias de ensino voltadas às reais dificuldades encontradas pelos profissionais de saúde na assistência à PCR (ALVES; BARBOSA; FARIA, 2013; LYRA et al., 2012). Acredita-se que tal conhecimento contribuirá em maior capacitação dos profissionais e da instituição hospitalar quanto à assistência prestada no suporte básico e avançado de vida, e sua relevância para a qualidade e para a segurança na prestação do cuidado. Este estudo teve por objetivo apresentar aspectos teóricos e assistenciais acerca do suporte avançado de vida durante a PCR.

\section{METODOLOGIA}

Trata-se de estudo descritivo, exploratório, do tipo revisão narrativa da literatura. Esta revisão se baseou principalmente na Diretriz de Ressuscitação Cardiopulmonar e Cuidados Cardiovasculares de Emergência da Sociedade Brasileira de Cardiologia publicadas em 2013 (GONZALEZ et al., 2013; SOCIEDADE BRASILEIRA DE CARDIOLOGIA, 2013).

Tais diretrizes tiveram seu conteúdo ampliado à luz de estudos. Optou-se por esse material, porque, conforme Tallo et al. (2013), o mesmo destaca que a qualidade das compressões torácicas (CT) continuava necessitando de melhorias; a carência de uniformidade entre os serviços médicos de emergência levavam a uma considerável variação na sobrevivência à PCR extrahospitalar e a maioria dessas permaneciam sem receber qualquer manobra de RCP de pessoas presentes no local. Além disso, as novas diretrizes trazem recomendações para melhorar a taxa de sobrevivência de pessoas reanimadas por meio de uma nova ênfase nos cuidados pós-reanimação e reforça a importância da qualidade da RCP como a chave na sobrevivência das vítimas de PCR .

A realização da revisão ainda se ancorou nas etapas propostas por Ganong (1987): formulação da questão norteadora; delimitação dos critérios de seleção; busca dos artigos nas bases de dados; seleção dos artigos; leitura exaustiva do material selecionado; organização das informações extraídas dos artigos e sua apresentação na presente pesquisa. Assim, elaborou-se a questão norteadora: "Quais os aspectos teóricos e assistenciais, do suporte avançado de vida, existentes durante uma parada cardiorrespiratória? Em seguida, foram delimitados os critérios de seleção dos estudos: pertinência à questão norteadora; caracterização como artigo científico; publicação nos últimos cinco anos (2010 a 2014), a fim de contemplar evidências e artigos recentes; disponibilidade no idioma 
português; acessibilidade dos artigos na íntegra; não repetição nas bases de dados onde se fez a busca. Para ampliar a literatura, foram incluídos ainda livros-textos no corpus de material selecionado.

$\mathrm{Na}$ busca, foram utilizados os Descritores em Ciências da Saúde (DeCS) da Biblioteca Virtual em Saúde (BVS): Ressuscitação cardiopulmonar; Suporte Básico de Vida; Parada Cardiorrespiratória; Assistência ao Paciente. Realizou-se a busca da literatura nas bases de dados Literatura Internacional em Ciências da Saúde (MEDLINE), Literatura Latino-americana e do Caribe em Ciências da Saúde (LILACS) e Scientific Electronic Library Online (SciELO). Aplicando-se os descritores e critérios de inclusão, um total de dez artigos foram selecionados e aplicados no presente estudo.

\section{SUPORTE AVANÇADO DE VIDA}

\section{O Manejo da Via Aérea}

A escolha do melhor método de ventilação deve ser feita com base na experiência do socorrista, sendo aceitável a utilização do dispositivo de bolsa-válvulamáscara, isoladamente ou em combinação com a cânula orotraqueal, assim como a máscara laríngea, o combitube ou o tubo laríngeo. O uso de oxigênio a $100 \%$ é razoável durante as manobras de RCP com o objetivo de aumentar a oxi-hemoglobina arterial e a oferta de oxigênio. Embora a exposição prolongada a $100 \%$ seja tóxica, não existem evidências que ocorra toxicidade com a exposição breve, como no cenário da RCP em adultos (GONZALEZ et al., 2013; SOCIEDADE BRASILEIRA DE CARDIOLOGIA, 2013).

A ventilação com dispositivo bolsaválvula-máscara é um método aceitável para a ventilação durante as manobras de RCP, mas requer treinamento contínuo para seu uso adequado. Idealmente, esse dispositivo deve ser utilizado por dois socorristas. Durante a $\mathrm{RCP}$, devem ser realizadas duas ventilações após 30 compressões torácicas (SOCIEDADE BRASILEIRA DE CARDIOLOGIA, 2013).

No caso de PCR intra-hospitalar por FV/TV refratária e, principalmente, por AESP /assistolia, a ventilação com cânula orotraqueal é o método mais recomendado no manejo da via aérea. A interrupção da realização das compressões torácicas por motivo da intubação orotraqueal deverá ser minimizada ao extremo, e a intubação deverá ser realizada somente em momento oportuno, quando não for interferir com as outras manobras de ressuscitação. O treinamento e retreinamento nessa habilidade são recomendados para socorristas que realizam esse procedimento. Não há evidências na literatura sobre o melhor momento para realizar a intubação orotraqueal durante $\mathrm{O}$ atendimento da PCR (GONZALEZ et al., 
2013; SOCIEDADE BRASILEIRA DE CARDIOLOGIA, 2013).

Após a colocação da cânula traqueal, é necessário checar se o seu posicionamento está correto, o que é feito inicialmente pela avaliação clínica que consiste na visualização da expansão torácica e da condensação do tubo durante a ventilação e na ausculta em cinco pontos: epigástrio, base pulmonar esquerda, base pulmonar direita, ápice pulmonar esquerdo e ápice pulmonar direito, preferencialmente nessa ordem. Além disso, o posicionamento correto do tubo deve ser confirmado com a utilização de um dispositivo. O mais indicado é a capnografia quantitativa, mas na sua ausência podem-se utilizar dispositivos detectores esofágicos e detectores de $\mathrm{CO}_{2}$. Deve-se manter a ventilação e oxigenação com intervalo de uma ventilação a cada seis a oito segundos, o que corresponde de oito a dez ventilações por minuto de maneira assíncrona às compressões torácicas, que devem ser mantidas em frequência igual ou superior a 100 por minuto (GONZALEZ et al., 2013).

\section{A Monitorização Durante a PCR}

O dióxido de carbono exalado no final da expiração (expressado em $\mathrm{mmHg} \quad-$ $\left.\mathrm{PETCO}_{2}\right)$ detectado pela capnografia quantitativa em pacientes intubados é correlacionado com a qualidade da RCP e com o retorno da circulação espontânea
(RCE). Durante a PCR não tratada, a produção de $\mathrm{CO}_{2}$ é mantida, porém não existe liberação pelos pulmões, sendo a presença de débito cardíaco a maior determinante da liberação do $\mathrm{PETCO}_{2}$. Os valores do PETCO2 são correlacionados com o RCE e com a pressão de perfusão coronária. Valores $<10$ $\mathrm{mmHg}$ revelam pouca probabilidade de RCE, indicando a necessidade de melhora na qualidade da RCP (GONZALEZ et al., 2013; SOCIEDADE BRASILEIRA DE CARDIOLOGIA, 2013).

Outro mecanismo muito útil para a monitorização da RCP é a medida da pressão arterial diastólica (PAD) naqueles pacientes que dispõem de monitorização arterial invasiva no momento da PCR. Seu valor é correlacionado com a pressão de perfusão coronária e com o RCE. Nas situações em que a pressão de relaxamento (diastólica) é $<20$ $\mathrm{mmHg}$, é razoável considerar melhorar a qualidade da RCP, melhorando as compressões torácicas e as drogas vasoativas. Vale ressaltar que a presença de dispositivos arteriais também pode reduzir o tempo de interrupção da RCP na checagem de pulso em pacientes com atividade elétrica organizada (GONZALEZ et al., 2013; SOCIEDADE BRASILEIRA DE CARDIOLOGIA, 2013). Saturação venosa central < $30 \%$ é relacionada à impossibilidade de atingir o RCE; sugerindo-se então que, durante a PCR, é 
necessário manter valores acima de $30 \%$ (GONZALEZ et al., 2013).

Em adição, durante a monitorização durante a PCR, ao considerar que a adequada ressuscitação realizada pelo enfermeiro é fator determinante nos índices de sobrevivência dos episódios de PCR, e que ele é normalmente o primeiro profissional a se deparar com esse evento, a educação permanente permitirá restaurar o processo de vida, e não apenas prolongar o processo de morte dos indivíduos. Assim, recomenda-se aos serviços de saúde realizar treinamento periódico em RCP com a finalidade de capacitar as equipes, em especial o enfermeiro, para atendimento rápido, seguro e eficaz, dentro do que é preconizado, e manter a homogeneidade das condutas entre as equipes (ALVES; BARBOSA; FARIA, 2013).

\section{O Manejo da PCR}

A parada cardíaca pode ser causada por quatro ritmos: Fibrilação Ventricular (FV), Taquicardia Ventricular Sem Pulso (TVSP), Atividade Elétrica Sem Pulso (AESP) e Assistolia. A sobrevida dos pacientes depende da integração do SBV, do suporte avançado de vida em cardiologia (SAVC) e dos cuidados pós-ressuscitação (GONZALEZ et al., 2013).

As pausas durante as manobras de RCP devem ser minimizadas e restritas a checagem de ritmo, desfibrilação, checagem de pulso quando houver ritmo organizado e breve pausa para obtenção e confirmação de uma via aérea avançada. A monitorização da qualidade da RCP é fortemente recomendada. O atraso no início da administração de vasopressores para além dos primeiros cinco minutos de PCR, bem como a demora em instalar via aérea avançada podem estar associados a pior prognóstico. Assim, pode-se sugerir o início do uso de vasopressores nos primeiros ciclos de RCP (GONZALEZ et al., 2013; SOCIEDADE BRASILEIRA DE CARDIOLOGIA, 2013).

Durante a tentativa de ressuscitação, o socorrista deve tentar identificar a causa da PCR - diagnóstico diferencial. A maioria das causas de parada pode ser resumida na memorização mnemônica "5 Hs e 5 Ts", a saber: Hipóxia, Hipovolemia, Hidrogênio (acidose), Hiper/Hipocalemia, Hipotermia; Tóxicos, Tamponamento cardíaco, Tensão no tórax (pneumotórax hipertensivo), Trombose coronária (infarto agudo do miocárdio), Tromboembolismo pulmonar (GONZALEZ et al., 2013; SOCIEDADE BRASILEIRA DE CARDIOLOGIA, 2013).

Para o ideal atendimento da PCR, além de ênfase na RCP de boa qualidade, deve-se atentar ao papel de cada um na equipe de ressuscitação. $\mathrm{O}$ treinamento do atendimento de PCR em equipe minimiza erros e é recomendado. Os dois princípios fundamentais do bom trabalho em equipe são: 
liderança e comunicação efetiva. Assim, a cada atendimento, deve haver um profissional que assuma o papel de líder na condução do caso. Esse profissional deve garantir que todas as tarefas sejam compreendidas e executadas pelos diferentes membros da equipe, incorporar novas informações, reavaliar o caso, centralizar a comunicação entre os membros da equipe e avaliar o desempenho de seus colegas, garantindo RCP de boa qualidade, controle adequado da via aérea e segurança na manipulação do desfibrilador (GONZALEZ et al., 2013; SILVA; MACHADO, 2013).

\section{O Tratamento da Fibrilação Ventricular e} Taquicardia Ventricular sem Pulso

Quando a monitorização com desfibrilador manual revela ritmo de FV/TVSP, a prioridade deve ser a desfibrilação o mais precoce possível, assim que disponível, uma vez que duração da arritmia é fator prognóstico para o sucesso da desfibrilação, sendo máximo se a desfibrilação é realizada com desfibrilador manual ou automático em até 3 minutos do início da FV. Durante a reanimação, devem se consideradas drogas vasopressoras e antiarrítmicas, bem como identificar e tratar causas potencialmente reversíveis (GONZALEZ et al., 2013; SOCIEDADE BRASILEIRA DE CARDIOLOGIA, 2013).
Se um desfibrilador bifásico estiver disponível, a energia do choque deve ser entre 120 e 200 Joules ( $\mathrm{J})$ conforme as orientações do fabricante. Se o socorrista desconhece as orientações do fabricante o choque deve ser administrado com a energia máxima disponível no aparelho. Se um desfibrilador monofásico estiver disponível, o choque deve ser administrado com 360J assim como os choques subsequentes (GONZALEZ et al., 2013; SOCIEDADE BRASILEIRA DE CARDIOLOGIA, 2013).

Após o primeiro choque, preferencialmente com desfibrilador bifásico, procede-se RCP por dois minutos, seguida de checagem de ritmo no monitor. Caso FV/TV persista, procede-se a um novo choque de alta energia, seguido por RCP durante dois minutos. O melhor momento para administrar o vasopressor não é estabelecido, devendo-se considerar seu início após o estabelecimento do acesso venoso. A administração precoce poderia otimizar o fluxo sanguíneo miocárdico antes do próximo choque. Há evidências sugerindo que o início precoce das drogas melhore o prognóstico (GONZALEZ et al., 2013). Essas evidências também indicam que, sendo a PCR uma emergência de alto impacto nos índices de mortalidade, o enfermeiro exerce um papel fundamental no atendimento juntamente com a equipe médica, considerando a sobrevivência dependente diretamente do sucesso dessa atuação como 
participante da equipe multiprofissional (SILVA; MACHADO, 2013).

Em qualquer ritmo de PCR, a primeira droga a ser utilizada deve ser um vasopressor. Embora o nível de evidência seja limitado, recomenda-se administração de adrenalina 1 mg a cada três a cinco minutos (GONZALEZ et al., 2013; SOCIEDADE BRASILEIRA DE CARDIOLOGIA, 2013).

A primeira ou segunda dose de adrenalina pode ser substituída por vasopressina 40 U. Caso haja persistência de FV ou TVSP, apesar da RCP, desfibrilação e vasopressor, indica-se um antiarrítmico: amiodarona (antiarrítmico de escolha) ou lidocaína. A amiodarona, um antiarrítmico classe III de Vaughan-Williams, é a droga antiarrítmica de primeira escolha no tratamento da FV/TVSP refratária após a droga vasopressora e nova desfibrilação (GONZALEZ et al., 2013; SOCIEDADE BRASILEIRA DE CARDIOLOGIA, 2013).

\section{O Tratamento da Assistolia e da Atividade} Elétrica sem Pulso

São ritmos em que a desfibrilação não está indicada. Deve-se, então, promover RCP de boa qualidade, aplicar as drogas indicadas e procurar identificar e tratar as causas reversíveis. Se no momento da checagem de ritmo, após dois minutos contínuos de RCP, houver um ritmo organizado no monitor, procede-se à checagem do pulso central carotídeo por cinco a dez segundos. Caso não haja pulso palpável nesse período, identificase AESP (GONZALEZ et al., 2013; SOCIEDADE BRASILEIRA DE CARDIOLOGIA, 2013).

Para ritmo de Assistolia ou AESP, um vasopressor, adrenalina ou vasopressina pode ser administrado com o objetivo de incrementar o fluxo sanguíneo cerebral e miocárdico. O uso rotineiro de atropina não é recomendado. O uso da vasopressina no lugar da primeira ou segunda dose de adrenalina pode ser realizado, mas metanálise não demonstrou diferenças entre as duas para nenhum dos ritmos de PCR. Não há evidência clara de benefício terapêutico com uso rotineiro de atropina no tratamento da PCR em AESP (GONZALEZ et al., 2013).

AESP e Assistolia podem ser causadas por condições reversíveis e tratadas com sucesso se forem detectadas. Durante os dois minutos de RCP, os socorristas devem lembrar dos "5Hs e 5Ts". Na AESP, quando existe a suspeita de um tromboembolismo pulmonar, a administração empírica de trombolíticos deve ser considerada (GONZALEZ et al., 2013; SOCIEDADE BRASILEIRA DE CARDIOLOGIA, 2013).

\section{As Vias para a Administração de Medicamento}

Durante a parada cardíaca a prioridade sempre será administrar RCP de boa 
qualidade e desfibrilação imediata; a administração de drogas será secundária. Depois da tentativa de desfibrilação, os socorristas devem estabelecer um acesso intravenoso (IV) ou intraósseo (IO), sem interrupção das compressões torácicas (GONZALEZ et al., 2013; SOCIEDADE BRASILEIRA DE CARDIOLOGIA, 2013).

Deve-se escolher, de preferência, o acesso venoso periférico nos membros superiores (veia antecubital). Se não for possível estabelecer acesso IV, a via intraóssea (IO), para administração de drogas, pode proporcionar concentrações plasmáticas adequadas, similares às alcançadas pelo acesso intravenoso. A administração de medicamentos por um acesso central pode ser considerada se não houver nenhuma contraindicação. Estudos têm demonstrado que drogas como lidocaína, adrenalina, atropina, naloxone e vasopressina podem ser absorvidas por via endotraqueal. Porém, a administração intravenosa (IV) ou intraóssea (IO) de medicamentos é preferível à administração endotraqueal (GONZALEZ et al., 2013).

\section{A Relevância dos Cuidados Pós-} ressuscitação Cardiopulmonar

Segundo Tallo et al. (2013), a maioria das mortes após reanimação ocorre nas primeiras horas pós-retorno a circulação espontânea. Por isso, toda a atenção deve ser voltada na monitorização e tratamento desses pacientes. O manuseio do paciente pós-parada cardíaca é complexo e deve tratar vários problemas importantes simultaneamente. As questões a serem abordadas incluem a determinação e tratamento da causa da parada cardíaca; a minimização da lesão cerebral; o manuseio da disfunção cardiovascular e a correção dos problemas que possam surgir a partir da isquemia global e lesão de reperfusão.

Cuidados organizados pós-PCR com ênfase em programas multidisciplinares têm como finalidade diminuir, numa fase inicial, a mortalidade associada à instabilidade hemodinâmica e, como consequência, limitar o dano cerebral e a lesão nos demais órgãos. O tratamento deve estar direcionado para disponibilizar um suporte que inclua ressuscitação volêmica, uso de drogas vasoativas, ventilação mecânica e o emprego de dispositivos de assistência circulatória (CAMPANHARO; MOREIRA; BATISTA, 2012; SOCIEDADE BRASILEIRA DE CARDIOLOGIA, 2013). Assim, considerando a complexidade da PCR e a necessidade de cuidados de qualidade também após a PCR, torna-se importante uma educação continuada sobre PCR e RCP, para a qual se pode elaborar, por exemplo, guia que servirá como suporte teórico para a padronização e melhoria do desempenho da equipe (SILVA; MACHADO, 2013). 
Rodrigues e Peres (2013) afirmam que, considerando a complexidade, ainda no que tange à capacitação, outra estratégia útil é a aplicação de ambientes virtuais de aprendizagem, sobretudo em cursos de graduação, de forma coerente, responsável e consistente em auxílio ao ensino tradicional. Essa estratégia vem demonstrando ser uma forma eficiente de construir conhecimento, fomentar a autonomia do graduando na busca e aprofundamento de conteúdos, desenvolver habilidades, melhorar a sua comunicação e trabalhar em conjunto, além de representar excelente oportunidade de capacitação profissional (SANTOS et al., 2012).

\section{CONSIDERAÇÕES FINAIS}

A presente revisão permitiu apresentar as recomendações mais atuais e indicadas por fortes evidências para a assistência durante o SBV e SAV na PCR. Os estudos focaram, também, os aspectos relativos à necessidade de constante capacitação, treinamento, educação permanente em serviço para os profissionais, e ainda para leigos no assunto, a fim de se ter uma assistência de qualidade. Ressalta-se que o conhecimento acerca da temática em questão é de suma relevância para que se prestem cuidados ancorados em boas práticas recomendadas por fortes evidências e que, dessa maneira, culminem numa assistência segura e de alta qualidade.

\section{REFERÊNCIAS}

ALVES, C. A.; BARBOSA, C. N. S.; FARIA, H. T. G. Parada Cardiorrespiratória e enfermagem: o conhecimento acerca do suporte básico de vida. Cogitare Enfermagem, Curitiba, v. 18, n. 2, p. 296-301, 2013.

CAMPANHARO, C. R. V.; MOREIRA, R. S. L.; BATISTA, R. E. A. Ressuscitação cardiopulmonar: novas diretrizes de atendimento. Acta Paulista de Enfermagem, São Paulo, v. 25, n. 3, p. 483, 2012.

GANONG, L. H. Integrative reviews of nursing research. Research Nurs Health, v. 10, n. 1, p. 1-11, mar. 1987.

GOLIN, V.; SPROVIERI, S. R. S. Condutas em urgências e emergências para o clínico. São Paulo: Atheneu, 2008.

GONZALEZ, M. M.; TIMERMAN, S.; OLIVEIRA, R. G.; POLASTRI, T. F.; DALLAN, L. A. P.; ARAÚJO, S.; LAGE, S. G.; SCHMIDT, A.; BERNOCHE, C. S. M.; CANESIN, M. F.; MANCUSO, F. J. N.; FAVARATO, M. H. Diretriz de Ressuscitação Cardiopulmonar e Cuidados Cardiovasculares de Emergência da Sociedade Brasileira de Cardiologia: Resumo Executivo. Arquivos Brasileiros de Cardiologia, Rio de Janeiro, v. 100, n. 2, p. 105-113, 2013.

LYRA, P. F.; CORDEIRO, D. E. F.; GOIS, A. C. R.; MUNIZ, F. N.; LEÔNIDAS, G. M.; SOBRINHO, C. R. M. R. Programa de educação em reanimação cardiorrespiratória: ensinando a salvar vidas. Revista Brasileira de Educação Médica, Rio de Janeiro, v. 36, n. 4, p. 570-573, 2012.

MENDES, K. dal S.; SILVEIRA, R. C. de C. P.; GALVÃO, C. M. Revisão Integrativa: método de pesquisa para a incorporação de evidências na saúde e na enfermagem. Texto $e$ 
Contexto Enfermagem, Florianópolis, v. 17, n. 4, p. 758-764, out-dez 2008.

RIBEIRO, L. G.; GERMANO, R.; MENEZES, P. L.; SCHMIDT, A.; PAZINFILHO, A. Estudantes de Medicina Ensinam Ressuscitação Cardiopulmonar a Alunos do Fundamental. Arquivos Brasileiros de Cardiologia, Rio de Janeiro, v. 101, n. 4, p. 328-335, 2013.

RODRIGUES, R. C. V.; PERES, H. H. C. Desenvolvimento de Ambiente Virtual de Aprendizagem em Enfermagem sobre ressuscitação cardiorrespiratória em neonatologia. Revista da Escola de Enfermagem da USP, São Paulo, v. 47, n. 1, p. 235-241, 2013.

SANTOS, M. C.; BERNARDES, A.; GABRIEL, C. S.; ÉVORA, Y. D. M.; ROCHA, F. L. R. O processo comunicativo no Serviço de Atendimento Móvel de Urgência (SAMU-192). Revista Gaúcha de Enfermagem, Porto Alegre, v. 33, n. 1, p. 6976, 2012.

SILVA, A. B.; MACHADO, R. C.

Elaboração de guia teórico de atendimento em parada cardiorrespiratória para enfermeiros. Revista da Rede de Enfermagem do Nordeste, Fortaleza, v. 14, n. 4, p. 1014-1021, 2013.

\section{SOCIEDADE BRASILEIRA DE} CARDIOLOGIA (SBC). I Diretriz de

Ressuscitação Cardiopulmonar e Cuidados Cardiovasculares de Emergência da Sociedade Brasileira de Cardiologia. Arquivos Brasileiros de Cardiologia, Rio de Janeiro, volume 101, N 2, Supl. 3, Agosto 2013.

TALLO, F. S.; MORAES JUNIOR, R.; GUIMARÃES, H. P.; LOPES, R. D.; LOPES, A. C. Atualização em reanimação cardiopulmonar: uma revisão para o clínico. Revista da Sociedade Brasileira de Clínica Médica, São Paulo, v. 10, n. 3, p. 194-200, 2013.
TREVILATO, Gerson. Guia prático de primeiros socorros - o que fazer em casos de emergência. São Paulo: Casa Publicadora Brasileira, 2001. 